\title{
Are employability and entrepreneurial measures for higher education relevant? Introducing AGILE reflection
}

\author{
Karen Knibbs
}

\section{University of Portsmouth, UK}

Key Words: entrepreneurship, enterprise, measures, employability, mindset, reflective practice

\begin{abstract}
This paper considers the relevance of current measures of employability and entrepreneurial (E\&E) outcomes for evaluating the longer term value of a course of Higher Education (HE) study. HE stakeholders continue to discuss whether exit performance metrics engender positive or negative responses, with educators arguing that E\&E outcomes should not focus heavily on hard skills, but a broader range of behavioural, attitudinal and mindset changes, claiming these provide greater longitudinal value for graduates. Through a critical review of literature and models, the paper explores; effectiveness of HE first destination metrics at capturing E\&E outcomes; whether explicit links exist between these; and what role students have in developing a narrative of their own E\&E outcomes? The discussion examines 'atheoretical' perspectives in E\&E education and issues of generalisability due to contextual variability, yet identifies common key mindset dimensions which are incorporated into a proposed 'AGILE' learning tool for students to reflect and develop a narrative of their E\&E related development against: Adaptable, Gatherer, Identity Awareness, Life-Long Learning and Enterprising capabilities. Thus it contributes an approach which HE stakeholders could consider the value of embedding within their own curricula, placing the onus on students to reflect, self-evaluate and record personalised 'small-wins'.
\end{abstract}

\section{Introduction: Relevance of current exit employment measures}

Higher education (HE) stakeholders (especially educators, administrators, leaders, policy makers and professional bodies) are increasingly driven to achieve against a range of metrics including student satisfaction, employment levels on exit (HESA, 2016), research generation, knowledge transfer income and teaching excellence. Employability metrics are publicly available data and as such may have an effect on higher education institution (HEI) reputations, retention rates and course demand (Quintini and Pouliakas, 2014; Caza, Brower and Wayne, 2015; Kakouris, 2015). Scrutiny and focus on achieving against these metrics can create responses and activities which may, ironically, be contradictory or unhelpful towards achieving intended objectives (Holmes, 2013a). For example, mentoring support for students seeking placement does not necessarily improve numbers placed, even though it may indirectly enhance the employability of mentors

(Procter, 2012).

Whilst accepting that it is natural for HE stakeholders to review and implement changes in an effort to improve performance, we should ask, are the measures themselves relevant 
to current contexts of employability and enterprise development outcomes of a holistic HE experience?

"If employability is measured in the simplistic terms of whether or not a graduate has managed to secure a job within six months of graduating, it only provides a very vague and imprecise indication of what the student has gained." (Dacre Pool and Sewell, 2007, p278).

In order to respond to variable labour market circumstances, graduates are increasingly developing a portfolio career involving moving between employment, self-employment and freelancing (Tomlinson, 2012), which in turn necessitates adapting their personal identities and goals over time (Jensen and Jetten, 2015). Given a rising number of graduates are exploring a range of roles, firms, sectors and self-/employment modes (Faggio and Silva, 2014), why are HE outcomes still predominantly measured by one-off metrics such as the Destination of Leavers from Higher Education (DLHE)? This survey currently records what graduates are doing just six months after exiting from UK courses (HESA 2016), which, this paper will contend, does not provide an effective indication of the life-long value of HE (Holmes 2013a; Fletcher-Brown et al 2015). Relatedly, employability scholars claim measuring the level and type of exit employment of a graduate is too rudimentary a measure (Helyer and Lee, 2014). Perhaps this adds weight to arguments that a single-point exit employment measure is not relevant as a means of capturing the longer-term value of a HE course of study, nor the various paths graduates take between working for others and themselves? Holmes (2013b) recommends longitudinal measures which could include tracking not only roles and employment situations, but the extracted learning gain, effectuation, personality, identity and behavioural changes longer term, over what he calls a hybrid “trajectory” (pp. 1052).

Are E\&E outcomes mutually exclusive or conflated in this measurement exercise? Let us next consider definitions of "employment" and "employability" and explore if explicit links exist between each, against the context of effective E\&E measurement.

\section{'Employability': neither skills nor static employment status}

There appears to be a tendency in HE, to evaluate employability in terms of hard skills which may be technical, discipline or role specific (Bridgstock, 2009; Rae, Martin, Antcliff, and Hannon, 2012), at the expense of soft skills such as personality traits and attitudinal components (Jackson, 2015; Kalfa and Taska, 2015). Holmes (2013a) is a critic of skills-based employability terminology, claiming many related models have rarely been developed as a result of empirical research and even more alarmingly, feature over-dependence on reconstituted cross-references to existing work, to the point of overdistillation of the original meanings of each individual contribution. The outcome has generated a confusing array of contradictory skills lists, so he advocates exploration of non-skills based measures, to evaluate employability outcomes. Key to this, according to Sarasvathy, Kumar, York and Bhagavatula (2014) is longitudinal research around "selfeffectuation" which considers personalised development of dimensions such as changes in identity, self-awareness, embracing a lifelong learning approach and adoption of a growth mind-set. 
"The relative dimension of employability implies that each graduate is in competition with other graduates with similar qualifications and education and therefore that employability depends on the relative value of credentials. The subjective dimension of employability implies that graduates' attitudes, beliefs and orientations towards the labour market may influence the way they perceive the issue of employability, respond to the increasing positional competition and thus manage their own employability." (Roulin and Bangerter, 2013, p23).

In a competitive employment market, students are attempting to position themselves against others graduating at the same time with similar credentials. Yet, whilst employers attempt to compare applicants on an individual basis at the point of recruitment, HEIs measure employability using whole cohort statistics. Although this generalisation is understandable to facilitate recording and comparison at scale, perhaps critical additional insights could be gained from existing student record systems, which provide individualised student learning-gain metadata (Chevalier, Gibbons, Thorpe, Snell and Hoskins, 2009)? After all, any related HE learning activity is limited in its ability to stimulate employability 'success' in all respondents equally, as a students' situational context (gender, ethnicity, culture, prior education, geographic location, familial and personal financial status, exposure to entrepreneurial ventures etc.), as well as their own attitudes, beliefs and values, will generate relative outcomes for individual students (Blenker et al, 2012).

Attempting to address this variability, the introduction of the HEAR (Higher Education Achievement Record) provides a recording tool owned and populated by information from a students' institution, Yet it has limited scope for enabling students themselves to add reflective accounts of the value of any learning or extra-curricular activities listed. Such introspective information, which could be substantiated by personal tutors and other stakeholders, might offer greater depth towards achieving HEAR's own aim of providing a "richer record of student activity" which "adds value to the student experience through its potential to encourage students to make the best use of their time at university" (http://www.hear.ac.uk/about).

\section{Entrepreneurship Education: an “atheoretical” field?}

"The previous decade has witnessed a global increase in entrepreneurship education programme provision aimed at encouraging entrepreneurial activity, business start-ups and entrepreneurial mindsets”, Pickernell, Packham, Jones, Miller and Thomas (2011, p184), citing Fayolle et al.

Although various course programmes or modules in $\mathrm{HE}$ are dedicated to acquiring entrepreneurial learning, debates continue regarding whether development of entrepreneurial competence is something innate or possible to be learned (Gibb, Hannon, Price and Robertson, 2014; Lahm and Heriot, 2013). There exist a variety of interpretations of 'enterprise' and 'entrepreneurship' (Young, 2014) and each author who reviews them finds something different, as their evidence comes from specific contexts 
(micro-firms, rural lifestyle SMEs, Undergraduate Business students, Postgraduate STEM students, spin-outs vs. embedded internships, social enterprise and charitable organisations etc; O’Leary, 2012). Woollard (2010) suggests this creates an "atheoretical" field where one model of enterprise education (EE) is not truly possible. He argues EE theories need to "incorporate conjectures from diverse perspectives..., examining different approaches [to find] commonalities, contradictions and anomalies to stimulate development of new concepts” p415. Hence EE approaches span learning 'for', 'about, and 'through' enterprise, aimed at enabling the student to think and act in enterprising ways (Pittaway and Cope, 2007), with self-employment or venture creation being a possible, rather than intended outcome (Hartshorne, 2002). Whilst Woollard's (2010) EE model applies to how a whole intuition may instill an entrepreneurial ecosystem, he also sets out a range of moderating factors and operational inputs which generate benefits at the individual level, chief amongst these being opportunity awareness, acquisition and deployment of resources. Sustaining the gains from such activities in the longer term however is the most challenging aspect, which he further posits relies upon all stakeholders behaving in an entrepreneurial manner, creating a virtuous circle of benefits and peer interaction.

Rae et al (2012) attempts to illustrate how entrepreneurial learning needs to be applied to relevant contexts for students to develop "skills, knowledge and attributes needed to apply creative ideas and innovations to practical situations" (p.382). He emphasises how setting learning within situational contexts encourages the application of initiative, independence, creativity and problem solving to identify and work on opportunities directly, utilising leadership, resourcefulness and responding to challenges. Boon, Van der Klink and Janssen (2013, p.213) agree that development of entrepreneurial competence is an experiential process, involving facing the challenge of new venture creation (experience); negotiating relationships (social interaction); and trying to overcome issues, by following role models and good practice (observation); subsequently evaluating experiences, to draw lessons from them (reflection). Significantly, Boon et al's model illustrates the difference between learning (which can result in inert, passive responses of students if curricula are ineffectively developed), and leadership, which requires proactive participation (i.e. entrepreneurial behaviours), in order for students to apply theories and test them in formal and informal, practical situations. Hence, active participation and reflection are critical components of the learning process. As Jones (2010) states; "entrepreneurship education leads to unique life-long skills” p436, cited in O’Leary (2012).

\section{Explicit links between Employability and Enterprise outcomes?}

Roulin and Bangerter's (2013) characterisation of employability dimensions, based on students with placement experience, found significantly improved learning where higher levels of proactivity were adopted. Accordingly, Tymon (2013) identified proactivity as key to improving employability, in her work which draws a parallel between subjectivist and opportunistic behaviours amongst students. Her evidence finds proactive students tend to exhibit a positive attitude towards themselves, which stimulates their ongoing learning and therefore, their employability in the longer-term. Of course, not all students 
are equally 'proactive' hence do not equally recognize nor exploit opportunities. Soetano (2015) and Rae (2017) explore how capitalizing on networks is crucial for entrepreneurial success, alongside having an optimistic, growth attitude to learning, with Storey (2011) finding that proactive entrepreneurs who remain open to chance, feature heavily in higher performing smaller firms.

Following Woollard's (2010) call for clearer conceptualisation, Knibbs, Fletcher-Brown and Middleton (2015) proposed the 'EmployaGility' model in order to draw all of these points together and overlay them in a way which illustrates the gains from adapting ones' learning approach. Their model highlights how students can move towards a "sweetspot” in their E\&E learning provided they:

- Actively engage in their learning by applying understanding of the subject

- Develop self-awareness through reflection

- Acknowledge how their identity changes over time

- Generate opportunities when applying an enterprising attitude.

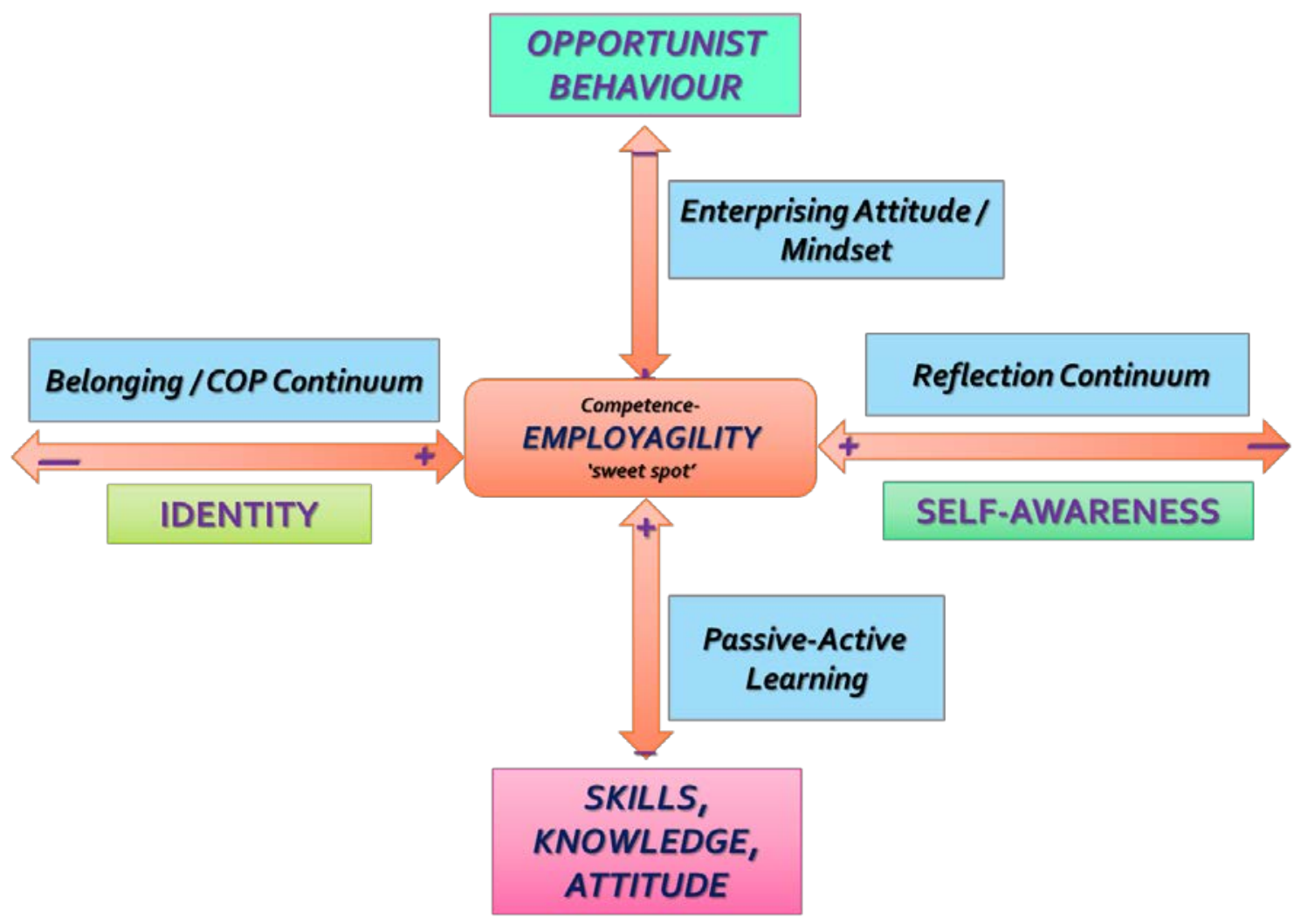

Figure 1: Elements of EmployaGility Development, (Knibbs, Fletcher-Brown and Middleton, 2015).

They assert, HE courses expose students to unique opportunities to leverage value from interactions and relationships between various stakeholders inside and outside of their institution, which they may not be conscious of! Hence students may need assistance to 
be more aware of their belonging to 'Communities Of Practice' COP (Wenger, 2010) and relative development of expertise from novice, to intermediate and professional levels, as they progress through their course. By applying reflective techniques, students could be supported to perceive links between their own approach and successful outcomes, or "small wins" (Amabile and Kramer, 2011). The ultimate aim is to enhance not only immediate, but longer term work, career and personal development. For EE practitioners and educators, rather than lamenting this apparent lack of awareness, perhaps we should consider to what extent the art of reflection has truly been explored in our EE approaches?

“...learning is not an optional extra, but is central to the entrepreneurial process: Effective entrepreneurs are exceptional learners. They learn from everything. They learn from customers, suppliers, and especially competitors. They learn from employees and associates. They learn from other entrepreneurs. They learn from experience. They learn by doing”, Harrison and Leitch, 2005, p.356, citing Smilor (1997, p. 344).

Exploring when and how learning happens, Storey (2011) identified that 'human capital' is seen as a proxy for educational attainment, but that 'growth' in learning is volatile, not linear or cumulative. In order to learn, entrepreneurs have to 'un-learn' and 'de-learn', particularly where failures occur. Having the resilience to tackle each of the consequent dips and turns, requires motivation, optimism and chance, which are also highly contextually dependent, subjective and can be affected by unanticipated variables at any time. Relatedly, Fletcher-Brown et al (2015) found where HE learning is contextualised from the outset using 'live-client briefs', students' commitment to ongoing, continuous improvement is enhanced. What is interesting in their study however, is that even though their data was not collected from students on an explicitly 'Enterprise' pathway, entrepreneurial capability development, behaviours and attitudes were expressly mentioned as outcomes from this type of applied learning.

Employability experts also support that entrepreneurial competencies are valuable in any working context, which can involve acting 'intrapreneurially' (harnessing enterprising thinking in a larger organisation), not just within a start-up working environment (Boon et al, 2013). Kalfa and Taksa (2015) agree, finding when students are put into situations calling for an enterprising approach, further enhanced with real-life outcomes, they are better able to link their own performance to application of their knowledge and skills, with their level of success. So why is it that destination measures see employability and enterprise as mutually exclusive outcomes?

\section{Methodological Approach}

The aim of this paper is to explore existing literature through a descriptive, narrative account of existing thinking, models and perspectives (Jones, 2004), in order to generate a conceptualisation for how to address any gaps identified. A narrative review was considered appropriate as it facilitates drawing of ideas into a holistic interpretation, which can be contributed to by existing theories, models and the reviewers' own experience (Jones, 2004) and follows many of the principles established in Jones, (2004) 
and Nabi, Liñán, Fayolle, Krueger and Walmsley’s (2017) systematic review process as detailed below.

\section{Scope and paper selection criteria}

Papers were, as far possible, selected on a structured basis (Jones, 2004; Nabi et al, 2017), using the following criteria:

- matching EBSCO Host library database searches for "entrepreneur*, enterprise, (higher) education, employability, performance measures, identity and mindset" (if potentially suitable papers were inaccessible, then repeated the search via Google Scholar)

- published after 2005 for currency, (if older, papers had to be frequently cited or considered 'seminal') in peer reviewed journals (with preference given to journal publications which linked directly to education, small business or entrepreneurship)

- $\quad$ providing perspectives from different countries with preference given to papers which had conducted a critical literature review of entrepreneurship education models and practice.

In order to map linkages and cross-references exposed across related areas of literature reviewed (education, employability and enterprise), Braun and Clarke's (2006) thematic mapping method was applied culminated in the following figure.

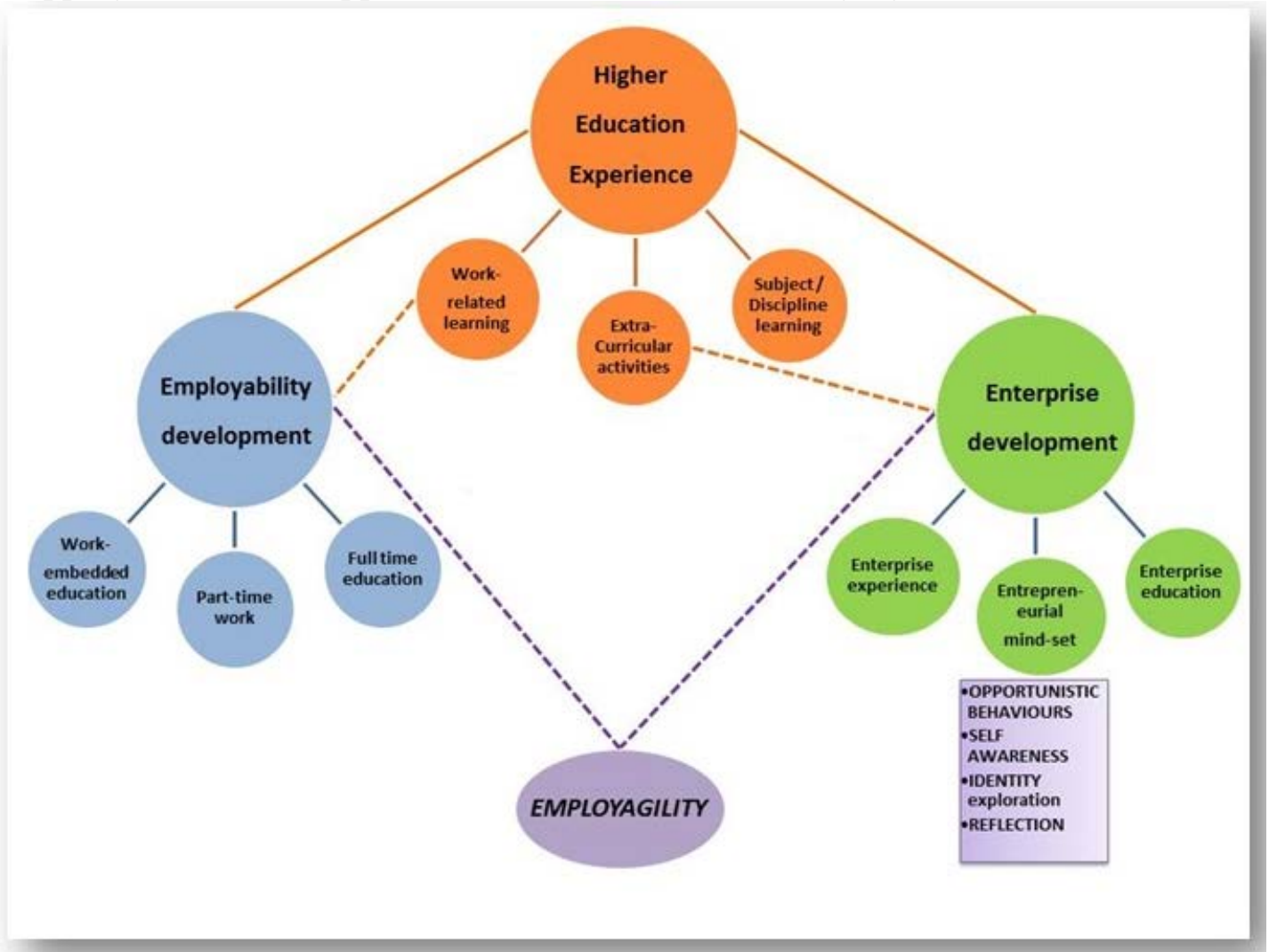

Figure 2: Higher Education EmployaGility thematic analysis map, (Knibbs, 2015)

The smaller bubbles represent functional elements of the student EE experience, whilst connectives help to identify where key terms emerge from each of the three core areas of 
literature. 'Employagility' (as proposed by Knibbs et al, 2015) is inferred as a positive outcome from a combination of these work, study and personal experiences in the HE context. The map also served as an aide memoire for ensuring coverage of all areas when searching for literature according to the selection criteria.

\section{Limitations}

The above process was applied to avoid bias creep towards authors' own published works and developmental content (Jones, 2004), papers were otherwise selected or rejected at the discretion of the author. As Baumeister (2013) supports, a qualitative, narrative research synthesis is appropriate when the attempting to review a range of divergent themes and methodological approaches which have changed over time, as this render meta-analytic aggregation impractical. Therefore, formal systematic review via databases or meta-analyses were not considered conducive to the creative approach needed to develop a conceptual outcome (Rowe, 2014).

\section{Research questions}

The discussion thus far has considered the changing HE employability context, definitions of key terms (employability, enterprise and entrepreneurship) and explored views suggesting that current $\mathrm{HE}$ exit measures of these as outcomes, are less relevant to the context than they might be. Contemporary models and published works regarding employability and entrepreneurship education outcomes will be considered through a narrative literature review to explore the following questions:

1. Do current HE first destination metrics effectively capture employability and entrepreneurial outcomes?

2. Do explicit links exist between HE employability and entrepreneurial outcomes?

3. What is the role of students in developing a narrative of their own employability and entrepreneurial outcomes?

\section{Capturing 'trajectory'; destinations and intentions, not locations}

Others have since agreed that current measures intended to record traditional employment lack the ability to effectively track entrepreneurial outcomes, arguing these focus too heavily on hard skills (Rae et al, 2012; Jackson, 2015; Kalfa and Taska, 2015), leading to calls to include a broader range of exit outcomes of gradates (Helyer and Lee, 2014; Holmes, 2013a). Studies criticising current employability models assert there is a danger of message apathy and over-simplification of employability as a tick-box lists of skills leaving development opportunities, leaving long term career planning largely unaddressed (Tymon 2013; Kakouris, 2015). Hence, exploring the broader relevance and value of attending University presents an important challenge for higher education stakeholders to evaluate other start-up and self-employment outcomes (Boon et al, 2013; Gibb et al, 2014; Lahm and Heriot, 2013; Sarasvathy et al, 2014).

As Nabi et al (2017) also explained however, setting-up a venture soon after graduating should not be considered a static or permanent state, as the process of turning that into a successful firm is likely to involve a lengthy incubation period, which further impacts the effectiveness of a one-off exit data collection point, as an employability or enterprise 
outcome measure. Equally, what makes evaluating entrepreneurial outcomes problematic with regards to entrepreneurship education, is the typical gestation period experienced by graduates developing self-employment. Hence, understanding the skills, attitudes and behaviours of students which may contribute towards their exit trajectory, becomes even more relevant; we should be looking at potential destinations and realisation of intentions, not current locations.

HEIs increasingly promote the entrepreneurial, even 'intrapraneurial' benefits of studying their courses, highlighting how their graduates thereby contribute to the economy as a result (Boon et al, 2013). Whilst no measure can be perfect, where metrics refer to a single point of reference, they lack sophistication and sensitivity to other related valuable gains from a University experience, which may be found in student records, CVs and portfolios, as well as analysis of metadata from institutional systems (Tsai and Gasevic, 2017).

\section{Entrepreneurship gaps in current employability models?}

As arguably the most well-known model of employability, Knight and Yorke's (2003) understanding and skills, and to a large degree metacognition (reflection) components of the USEM framework of employability are well-established in HE practice. Their model outlined the key student attributes demanded by employers identifying the core of an effective HEI employability curriculum: understanding (subject skills and knowledge), skilful practices (deployment), efficacy beliefs (personal skills and qualities) and metacognition (self-awareness and reflection). Further and crucially, they identified the need for graduates to use these skills in larger or small business contexts, arguing it will enhance graduate employability with SMEs (Yorke and Knight, 2004). Following this line of thought, McLarty (2005) suggested skills must be learned and encouraged at undergraduate level and embedded into the curriculum (Jones, Jones, Skinner and Packham, 2013).

As discussed earlier, changes in the employment landscape have stimulated hybrid graduate exit destinations including freelancing and consultancy, often via start-up and self-employment routes (Clinton et al, 2006). Indeed, career mobility itself offers opportunities for greater job fulfilment, whereby a variety of roles and workplaces enable heightened development of skills, knowledge and capabilities over time (Holmes, 2013a). This type of portfolio trajectory aligns well to that of an entrepreneur, as illustrated by Minniti and Bygrave's (2001) dynamic algorithm, which attempts to calculate the expected learning path of an entrepreneur as they make decisions. Their work emphasises that no single formula can possibly anticipate how an entrepreneur may act in a given situation. In fact, this is a positive outcome; being in a position to try a range of options, entrepreneurs learn to manage risk and uncertainty. They found that graduates utilised acquired knowledge and experience to follow the path that lead to success last time; dealing with inevitable failures by understanding the need to change direction; i.e. learning from failure.

Many universities have responded by elaborating lists of 'graduate attributes' in order to enable the development of generic skills and by encouraging their staff to adopt specific 
pedagogical tools for such ends. This approach is underpinned by the assumption that the acquisition and transferability of such skills can enhance students' human capital and, therefore their employability (Kalfa and Taska, 2015, p.580). As Cumming (2010, p3) points out, it's not just a lack of appropriate skills, but the wrong kinds of "attitudes and dispositions, which in turn prevent them from participating effectively in the workplace”, highlighting the paradoxical situation often observed of latent potential in some students or graduates who simply fail to capitalize on opportunities in front of them due to inaction (Tymon, 2013). This supports Gibb et al's (2014) argument that entrepreneurship should be taken into a wider interdisciplinary context, as, it is asserted, when students apply enterprising opportunistic behaviours, their employability outcomes are greatly enhanced. To date however, the interface between employability and enterprise has been largely unaddressed by existing employability concepts even though recruiters and investors increasingly base decisions on soft-skills and attitudinal disposition factors (Roulin and Bangerter, 2013).

Rae (2005) attempts to address this nuance in his narrative enquiry: “The term entrepreneurial learning therefore means learning to recognise and act on opportunities, and interacting socially to initiate, organise and manage ventures”, p324. He further argues that "Learning must be explored as a contextual and active rather than a purely educational process" which highlights another weakness in cohort level, cumulative exit performance metrics as they do not take into account the personal, psychological or sociological profile of the individual student, nor their level of proactivity and selfdevelopment during their HE experience. Current measures intended to record traditional employment therefore may lack the ability to effectively track entrepreneurial outcomes and are argued by many to focus too heavily on hard skills (Rae et al, 2012; Jackson 2015; Kalfa and Taska, 2015), leading to calls to include a broader range of exit outcomes of gradates (Helyer and Lee, 2014; Holmes, 2013a).

Andragogy scholars take the employability debate a step further and posit the HE experience should raise aspiration and stimulate proactive personality behaviours amongst students to enhance their human capital (Tymon, 2013; Kalfa and Taksa, 2015). Others agree, it is critical for students to develop self-awareness of their own employability and enterprise achievements as key elements towards improved measurement of HE learning gain (McGrath, Guerin, Harte, Frearson and Manville, 2015). Hence, there is an increasing call for educators to emphasise attitude development, reflectiveness and lifelong learning (Caza et al, 2015). Following these calls, Hernández-López, García-Almeida, Ballesteros-Rodríguez and De Saá-Pérez, 2016 argue extant research focus has emphasised what is done by HE institutions to improve exit outcomes when in fact, it should place onus on what students could and are doing for themselves.

\section{More explicit E\&E links?}

Employability has been the focus of wide-ranging and extensive debate ranging from 'employment' and ability to adapt to employment circumstances (Cumming, 2010; Wright, Brinkley and Clayton, 2010) and changes in domestic and international market conditions (Thompson, Clark, Walker and Whyatt, (2013). Hence graduates need to be 
aware of, and able to reflect on, how these changes affect their goals and alter their approach accordingly (Leibowitz, Ndebele, and Winberg, 2014). This involves switching jobs, employers and career paths several times (Marginson, 2014), which is not currently effectively tracked through cross-sectional exit destination data (HESA, 2016); Geneva ILO, 2017). This has lead Jones, Pickernell, Fisher and Netana, (2017) to conduct longitudinal studies of alumni many years after graduating, to explore their perceived longer term value of enterprise education to how they have adapted over time and their current situation, yet due to low numbers of respondents, issues of recall bias and the need for non-HE control groups, it is difficult to extract broader generalisations.

Guile and Lahiff (2013, p.17) recommend "combining workplace learning and study as a means of knowledge acquisition and skill formation”. Undergraduate internships are one such mechanism to facilitate this development, as experience of working across the business/university interface, involving genuine transference and co-creation of knowledge, enables students to develop into resourceful, adaptable employees (Helyer and Lee, 2014). Correspondingly, Knibbs et al, (2015) proposed their 'Employagility' concept to highlight how reflecting on one's own success of applying proactive and opportunistic behaviours, during interactions with internal or external HE stakeholders, can enable students to perceive improvements in their employability and enterprise outcomes. Mastery of new technologies combined with intellectual and intangible knowledge assets such as research, design, development, creativity, scientific enquiry, soft skills and human capital (Kalfa and Taksa, 2015) are increasingly demanded across all sectors. Relatedly, Bridgstock contended that "career management competence" should be promoted alongside more widely-held interpretations of employability (2009, p.32), which others claim need to include small firm freelancing, consultancy, start-up and intrapreneurship (Boon et al, 2013; Roulin and Bangerter, 2013). Hence a fixed and predictable set of skills and knowledge will not equip graduates adequately for the longer term (Holmes, 2013a; Nabi et al, 2017).

Encouragingly, many enterprise educators believe the concept of career mobility in itself offers opportunities for greater job fulfilment, whereby a variety of roles and workplaces enable heightened development of skills, knowledge and capabilities (Faggio and Silva, 2014; Lahm and Heriot, 2013). Yet the necessary adaptability will not be innate in all students. Whilst there is increasing recognition in employability models that development of entrepreneurial or enterprising attitudes, behaviours and approaches is needed (Gibb et al, 2014; Jones et al, 2017), these gains should not be considered as limited to students on explicitly enterprise dedicated programmes (Knight and Yorke, 2003; Sarasvathy et al, 2014). Hence the QAA (2018) and Scott, et al’s (2016) call for entrepreneurial learning to be included in curricula at all stages, putting pressure at Government policy level (Pickernell, Senyard, Jones, Packham and Ramsey, 2013) in the UK and more widely (Ciuhureanu AT, Gorski H and Balteş N (2011).

\section{HE Entrepreneurial outcomes}

Dacre Pool and Sewell (2007) recommend that employability measures provide more explicit definition of enterprise outcomes and not subvert these into employment types: 
"For many people employability is simply about getting a job, and the term is increasingly used carelessly and interchangeably with "enterprise”, which in turn is confused with “entrepreneurship”, p277.

The changing employment landscape has stimulated hybrid approaches involving portfolio careers consultancy, start-up and self-employment (Clinton, Totterdell and Wood, 2006), yet the previous discussion appears to define 'employability' as being 'employed', which Tymon (2013) disproves of. Equally, working for, or starting one's own SME should not be considered as a measure of how entrepreneurial a graduate is.

"Entrepreneurship is an inter-related process of creating, recognising and acting on opportunities, combining innovating, decision making and enaction...Learning is an emergent, sense-making process in which people develop the ability to act differently, comprising knowing, doing, and understanding why.....” (Rae, 2005, p272).

Nabi et al's (2017) systematic review listed entrepreneurship education (EE) outcomes as "enhanced student venture creation skills, knowledge, and attitudes and graduate business start-ups and overall job creation ultimately contributing to economic growth and development”, p277. Whilst many authors collectively support that entrepreneurial outcomes should be given increased scrutiny, only since 2012 has the DLHE collected information from graduates to indicate if they were self-employed or working for a smallto-medium sized enterprise (SME), (HESA 2016). The QAA's (2018) revised guidance indicates the difficultly of attempting to measure entrepreneurial outcomes in simplistic terms of having started one's own venture or working in a small firm upon graduation. Their below flowchart attempts to depict the finer detail of entrepreneurial development stages from awareness, to competence, mindset changes to effectiveness. As Jones et al (2017) support, developing an enhanced awareness or entrepreneurial mindset may not generate an immediately measurable outcome, but may enable a graduate to adapt and employ latent capabilities at an unknown future point, hence the QAA's figure attempts to illustrate what those changes might involve, making it easier for students to recognize them. Their HEA guidance document, which is informed by collaborative input from scholars, practitioners, academics, policy advisors and staff working in university entrepreneurial services, has become for many, an accepted source of definition of key terms. 


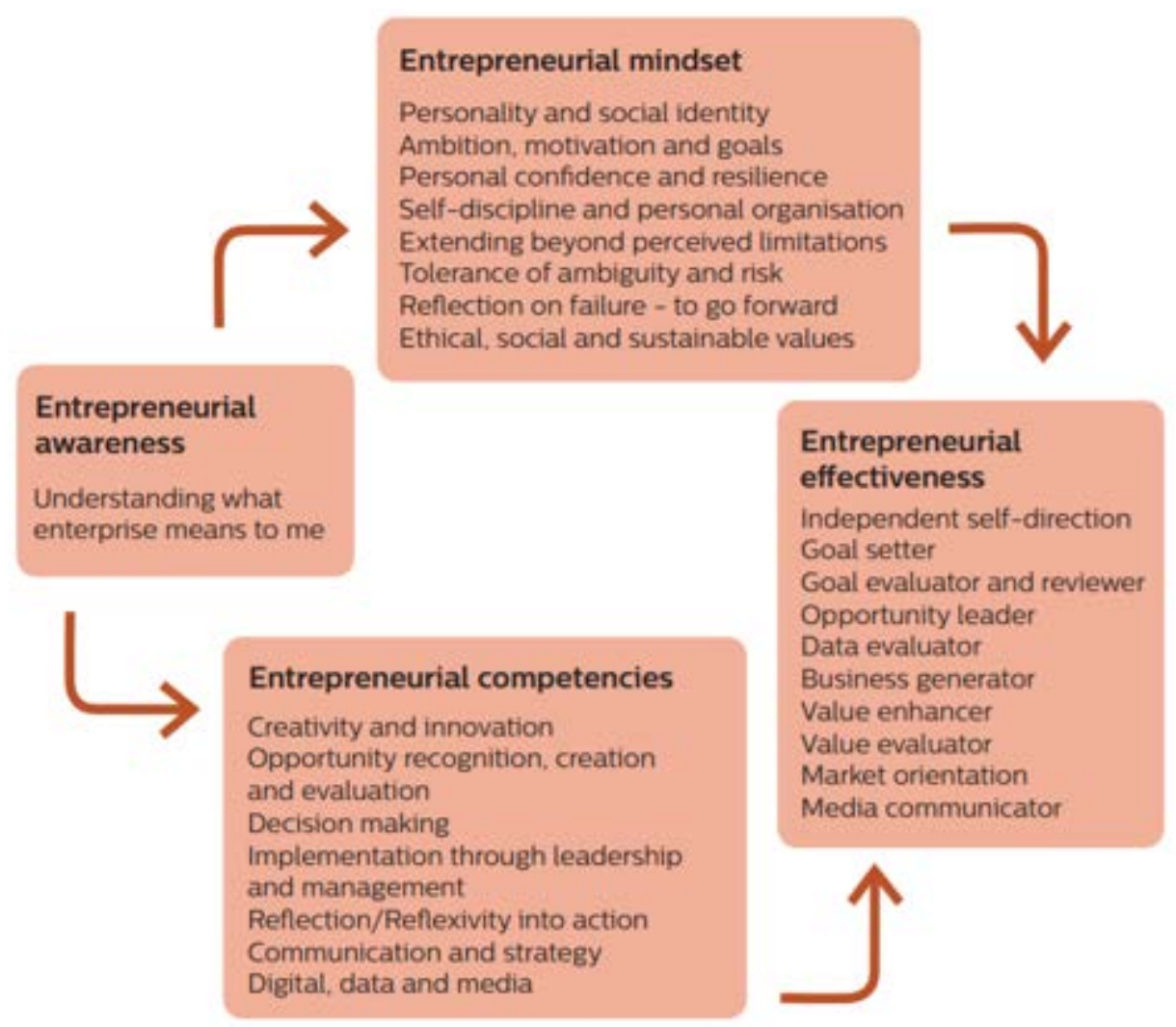

Figure 3: Connections between development entrepreneurial effectiveness and graduate outcomes, (QAA, 2018, p.21).

Are E\&E skills, attitudes and behaviours taught or developed?

Crossman and Clarke (2010) identify a range of stakeholders (including academic staff, personal tutors, recruitment teams, support service staff and employers) with whom it is critical for students to foster connections, creating networks (Pickernell et al, 2013) within different communities, both internally and externally of their university. Rae (2017) develops this further in his model of 'peripherality' in EE which advocates stimulating students to consider the value of seemingly unconnected peripheral, central and social experiences before, during and after their EE course. This process of establishing connections, where all parties actively engage in the learning process, has been found to be mutually beneficial and impacts over a career (Brooks and Everett 2008; Jackson, 2015). Fletcher-Brown et al (2015) address this through their study which adopted a holistic, '360 degree view' from the perspectives of three stakeholders: students, employers and educators, from various UK HEIs using live client projects in their curricula. The thematic analysis identified interactions between the three stakeholder groups during a course of study which enabled students to gather information and make contact with prospective employers. All three groups advocated the benefits to students of creating meaningful and purposive interpersonal contacts in maximising the results of the project at-hand, and indeed those students who reported the strongest ties with their clients gained the most success. 
During these stakeholder interactions, and as a student progresses through different stages of their course, Wenger (2010) found their identities morph, changing from outsider to 'belonging' within various communities of practice (CoP). Through this process, students develop increasing confidence and expertise in specific fields. For instance, as a student moves from the point of entry to a HEI programme, through the various levels of their course, internship period, final year, graduation and alumni, so their identity changes (Degn, 2015). Holmes (2013b) suggests this metamorphosis is a product of a type of social order, where positions, roles and identities available to individuals are negotiated outcomes of constant interaction and always essentially temporary; subject to possible contestation and change, within what he calls 'relational' or 'emergent identity' (p.1056). It therefore follows that new identities or trajectories emerge at each stage; from student identity, to graduate identity, leading into arguably the most revolutionary: professional identity.

Like Holmes (2013b), Porcheret, Main, Croft, McKinley, Hassell and Dziedzic, (2014). recognise identity as a critical factor in behavioural change related to personal and professional development. These authors are key leaders in the call to move the employability debate away from skills, towards discussion of entrepreneurial capabilities. Relatedly, Gibb et al (2014) highlight the importance of risk-taking behaviours in order to succeed in unknown circumstances, concluding that for graduates, career preparedness by itself is not enough, suggesting a new 'culture of learning', ie being prepared to follow an unpredictable path, is at the essence of knowledge creation. Taking appropriate action within unfamiliar and changing circumstances, requires a commitment to learning from one's mistakes and helps an individual develop their identity, which Rae (2007) suggests might feature in a self-assessment EE 'toolkit' measuring entrepreneurial and managerial capabilities of the individual, rather than being judged by the success of any venture they create.

Capabilities enable a range of functions which enable a person to do more with their lives (Hinchcliffe and Jolly, 2011), yet an individual must first stop to reflect in order to attempt to recognise their level of competence in achieving each capability, as Leibowitz et al (2013) acknowledges. Curriculum and other forms of intervention within HE which influence on-going identity development and support for students to reflect and recognise the changes are therefore inherently important. Thompson et al (2013) argue this development requires a commitment to coaching, mentoring and leadership style responses to be embedded within HE support provision.

Whose role is it anyway?

Governments around the globe are increasingly looking to HEIs as critical partners in the development of future labour force talent and for stimulation of economic growth through research (Ciuhureanu et al, 2011) innovation and knowledge development (Young, 2014). In preparing graduates for exit, HEIs seek to contribute to the development of human capital as a key component of value in the knowledge-based economy (Hernández-López et al, 2016). Plumb and Zamfir (2011), asserts that the task of developing the student's ongoing need for knowledge is a challenging one but suggests that students should be instilled with the feeling that they cannot survive as workers 
within the knowledge-based society without lifelong learning because "the spiral of knowledge [everlastingly] expands due to the application of knowledge to knowledge" (p. 484). Competence as a knowledge worker implies a level of flexibility and adaptability in order to be competitive in the job market of a fast-moving world (Kunert, Okole, Vorster, Brewin and Cullis, 2012).

HEIs facilitate related development not only by ensuring appropriate policies are in place, but by stimulating action by students to capitalise on available opportunities. They are also required to record the outcomes of appropriate curricula and work-related learning activities carried out against various impact factors. However, it is argued placing the onus on staff to 'provide' support, often results in a lack of engagement on the part of students. Relatedly, Tymon points out that the ability to gather people and resources, develop a sense of belonging and use networks to generate ideas, requires proactivity (2013). Critics in pedagogical research often lament the onus borne by academics and support services, rather than on students themselves, to take responsibility for development and utilisation of suitable networks (Hart, Davies, Aumann, Wenger, Aranda, Heaver and Wolff, 2013; Leibowitz et al, 2013).

If one adopts an attitude that opportunities are always present waiting to be discovered, then it is more productive for HEI stakeholders to draw attention to them and stimulate and catalyse students to act on them, rather than to take action on their behalf (Gibb et al, 2014; Sarasvarthy et al, 2014). Importantly for HEIs, increasing the number, range or type of employment related activities is unlikely to be the solution, as related gains are further limited by a students' ability to explain or evidence their unique employability (Blenker et al, 2012).

At this point, we must question, to what extent do existing employability and enterprise outcome measures provide a platform for effectively capturing when this adaptability happens, especially given statistics are predominately at general, cohort level and taken as a one-off cross-section of the current situation? These measures may be objective, but do they provide a meaningful indication of the holistic value of a university experience? Not forgetting of course, any 'change' may have differential impacts on individual students; for example, starting one’s own venture may provide less of a challenge for someone who has experienced it before, compared to someone who has not.

Whilst the HE achievement record (HEAR, 2016) is limited to verified information, albeit at the individual level, would student generated, subjective accounts fare any better? Even if the HEAR enabled students to add unofficial, unverified information to their personal portfolio, they may be providing the raw data of when changes occurred, but would they be adept at translating this into reflective narratives to explain to others, why, how and how effectively, they managed the related change? Which skills, attitudes or behaviours should students acquire and how can this reflective process be facilitated?

Hence, a critical question here is not whether current HE employability interventions provide the necessary employability curricula or support services, but what is the role of students themselves in developing the ability to generate a compelling employability 
narrative? Writing such a narrative is likely to present quite a challenge to students, who approach this from very different levels of experience and understanding. Likewise, the terms and expressions used by individual students would vary and be influenced by their culture and language (Marginson, 2014). Yet, by placing the onus on students themselves to self-record and self-evaluate 'small wins' (Amabile and Kramer, 2011), their deeper understanding and related ability would improve over time (Yeager and Dweck, 2012). Populating information into a personalised record could provide opportunities to correlate with other data already collected by HEIs and be used, with due permission, to generate a more sophisticated evaluation system (Chevalier et al, 2009).

Stein and Irvine's (2015) global survey of current and former college students in 14 countries, investigated participating students' perception of the role of their college education in preparing them for exit. Their results highlight that while educational activity supports improved career preparedness, helping students develop an entrepreneurial attitudinal 'mindset' (Gibb et al, 2014), equips students with stronger internal capabilities for adapting to new situations. This requires integrated and usable knowledge, rather than sets of compartmentalised and de-contextualised facts and taking responsibility for their own continuing, life-long learning (Ciuhureanu et al, 2011). Andragogy scholars, including Kalfa and Taksa (2015) therefore sensibly propose a focus on students themselves to record their own portfolio of evidence, for example, in order to establish how and when they have mastered competencies, developing a habit for understanding of their capabilities and the impact on their employment and enterprise trajectories.

\section{Summary of key findings}

The need for entrepreneurial gains to be explicitly linked to employability has received much attention from various governments (Quinitini and Pouliakas, 2014; Stein and Irvine, 2015), which may have catalysed the appearance of dedicated employability 'models' in literature (Knight and Yorke, 2003). When it comes to EE however, 'models' are seldom explicitly presented, as unlike employability provision, EE is embedded at varying strategic levels amongst HEIs, even in the same country (QAA, 2012; Scott, Penaluna and Thompson, 2016), from enterprise learning modules and programmes restricted to Business Schools, to multi-disciplinary opportunities, which may not always be credit bearing (Pickernell et al, 2011). Others further provide dedicated incubator centres and staff, offering training to internal and external audiences (Knibbs, 2015), with the aim of income generation, knowledge transfer and spin-out.

Where EE delivery, audiences and purposes vary, it renders proposal of generalisable models more difficult, as each is generated from a particular context, for example rural regeneration initiatives, arts and crafts ventures, biotechnology innovations, prior exposure to entrepreneurial firm activity, female entrepreneurship, maturity or ethnicity bias etc. (Rae, 2005; Rae et al, 2012). This may explain the propensity towards exploration of entrepreneurial characteristics, awareness, behaviours, capabilities and mindsets (Dweck, 2016; Gibb et al, 2014; Jones et al, 2017), which adds momentum to the aims for this research. Yet very few explicit links have been made in employability models or measures to entrepreneurial outcomes of the HE experience. 
We have explored the idea that current HE definitions and measures of employability do not account for the longer term value of a HE experience (Woodall, Hiller and Resnick, 2014) and examined the extent to which employability measures need to include more explicitly entrepreneurial outcomes (Kakouris, 2015). For example, the 'EmployaGility' concept (Fletcher-Brown et al, 2015) draws out critical components from established employability models (Yorke and Knight 2004; 2006; Dacre Pool and Sewell 2007, amongst others) and highlights the role of HEI stakeholders in preparing students for variable labour market circumstances (Faggio and Silva, 2014). This suggests that through a facilitated process of engagement with a range of HEI stakeholders, students can be supported to cultivate appropriate attitudinal dispositions (Moore and Moreton, 2017). The 'sweet-spot' lies at the intersection between identity theory (Falck, Heblich, and Luedemann, 2012; Jensen and Jetten, 2015) and the development of an appropriate mindset (Dweck, 2016). It is achieved when students concentrate on nurturing proactive behaviours and entrepreneurial attitudes, which, when combined with acquired knowledge and skills, identity-awareness and critical self-reflection, contribute to enhanced employment and entrepreneurial development.

The discussion also identified how early establishment of a proactive, enterprising approach in students can enhance their attitudes towards themselves, their ongoing learning, their work and ultimately, employability, in the longer-term (Stein and Irvine, 2015). HE stakeholders and curricula therefore need to create environments which stimulate students' development of identity understanding, self-esteem and attitudes that will lead to a flexible, agile approach to their work and a commitment to lifelong-learning (Caza et al, 2015), considering carefully variable experiential contexts.

\section{Special contribution}

Let us attempt to convey these key findings in a usable model for E\&E teaching and learning:

- Adaptability and agility

- Use of relationships and networks

- Identity Awareness

- Lifelong-learning

- Entrepreneurial mindset

These are depicted as the 'AGILE' mindset model (below), featuring 5 core dimensions. 


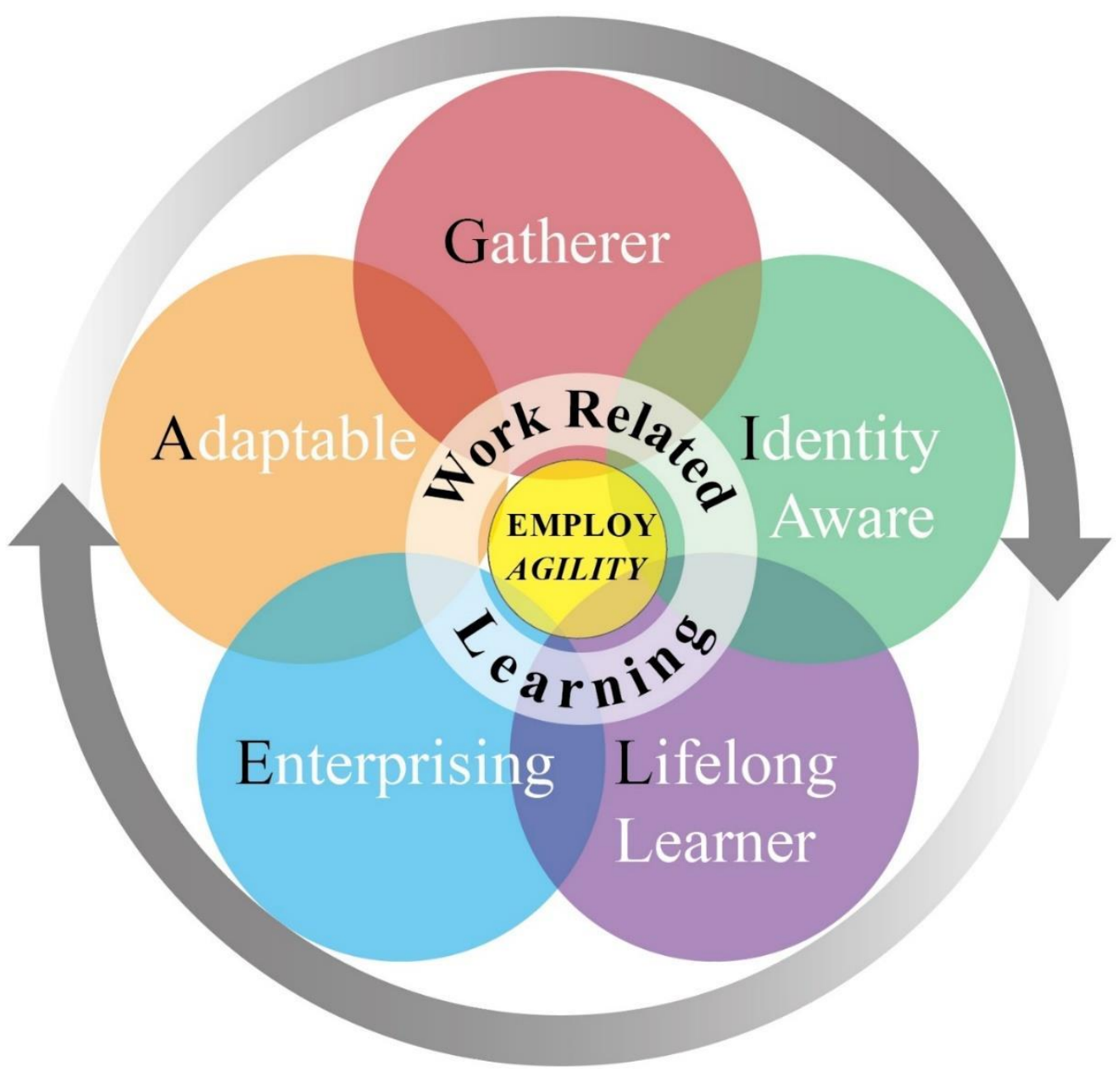

Figure 4: Proposed AGILE framework

How students could use the model

The model is illustrated using overlapping ellipses, to indicate connections between development of each dimension and the circular arrow highlights that development is not limited to a student's time in HE study, but continuous after graduation. Each dimension can framed as a set of reflective questions which students can ask of themselves and used to develop a narrative of their own experiences, to gauge how 'AGILE' they feel they have been. This process, when included in learning curricula, could provide a tool for reflection of the current state, as well as being revisited as part of personal development planning, to assess where changes and new 'small wins' have occurred over time:

Adaptable - to what extent have you shown resilience (especially when learning from failure through reflection - i.e. asking yourself: "What happened there? What went wrong and how could it be done differently to achieve better results next time?”). Try to think of times where you've been flexible or have adapted to changes and external environmental contexts, which could include local, regional, national or global experiences. 
Gatherer - to what extent would you have shown development of "networking” competencies? Think of situations where you've pro-actively sought out advice, information, and support or have done something to help others (i.e. gained buy-in / investment of mutually beneficial energy (not always money!) from other stakeholders). These could include interactions with anyone from home, school, work, hobbies or study.

Identity-Aware - how much do you use self-reflection to be more aware of your own role and skills in a given situation? Knowing your 'identity' includes appreciating roles you've taken within, and belonging to, “communities of practice” (see work by Wenger this means groups of other people like you that you belong to now, have been involved with in the past, or would like to join in the future). Think about how your identity changed over time (i.e. being a fresher, being on placement, being a graduate, to being a professional etc.) and what has belonging to each community enabled you to achieve?

Life-Long Learner - Celebrate every win, however small! Take time to give yourself credit! At the start of something new, your skills will have been lower than in the middle and at the end. Regularly keeping a diary of things you've done, learned and achieved can be very powerful, not only to remind yourself, but to evidence personal / professional development to future employers too! Try to use "proactive behaviours" i.e. seeking learning in all situations; recognising that learning starts before University and continues much after graduation, so you appreciate the need to develop in order to advance and achieve sustainability throughout your career for your life span.

Enterprising - this doesn't only mean starting your own business; it can involve keeping an open mind to opportunities; solving problems, thinking up new ideas. "Serendipity" means that unexpected positive outcomes often occur when you missed the original target. Think of times where you've bounced back after failing something, shown spirit or tried something different. Related skills include "initiative, independence, creativity, problem solving, identifying and working on opportunities, leadership, acting resourcefully and responding to challenges" (Rae 2007, p.611).

\section{Contribution to knowledge, policy and practice implications}

The review of employability approaches and models has identified limitations in relation to graduate exit measurement relevance to contemporary labour market conditions (Thompson et al, 2013) which would benefit from an increased focus on longer-range tracking (Holmes, 2013a) of entrepreneurial learning (Gibb et al, 2014) and mindset outcomes (Dweck, 2016). HE policy makers and quality assurance bodies should therefore consider further enhancements to existing exit metrics with an explicit onus on how student generated data could be included.

It is not the aim of this paper to provide a how-to, step-by-step guide for HEIs and academics to implement a revised E\&E curriculum, but to further discussion and reconceptualisation of employability frameworks to more explicitly encompass enterprise outcomes. HEI stakeholders are therefore urged to revisit current curricula to determine how these 5 dimensions could be embedded. An audit of this kind might help identify 
where agile practices might be strengthened and developed throughout undergraduate and postgraduate learning. However, we should be wary of spoon feeding or attempting to artificially create such opportunities, rather draw attention to them to stimulate and catalyse students to act upon them independently and proactively. The 5 'AGILE' dimensions therefore provide a starting point for the rethinking of $\mathrm{E} \& \mathrm{E}$ development in any discipline, whilst the research challenge is for pedagogy or, more appropriately andragogy scholars, to apply the dimensions and gather further evidence about the application of this tool. There is an important change of focus here, away from outcomes that are generated by what HE stakeholders do to support students, towards students reflecting on, evaluating and self-recording their own development.

Further, the 'AGILE' reflective tool has been adapted for a cloud capturing format (via Google forms) which enables students to populate their own record, see what other students have written and, importantly, staff (with permission), to collate and compare the language and terms used in entries, generating effectively a semantic glossary of terms, as a basis for thematic analysis research. This 'glossary' could further be used to ensure definitions of employability and enterprise are described in student-friendly terms. By encouraging students to revisit this record over time (for example, each academic year, as part of personal and professional development discussions), students can reflect on achievements against each dimension and identify gaps for improvement not just at one point, but for as long as they wish, even after their time in HE.

\section{Development opportunities}

The next stage of development of the model will include reaching out to recruiters, to gain their feedback on how 'AGILE' records might be used by employers (perhaps in professional development planning), or even as an additional information source, (provided confidentiality issues are handled correctly), for evaluating candidates. These are some of the special contributions which it is hoped 'AGILE' can offer to existing employability and enterprise outcome evaluation in HE; by placing the recording responsibility on students themselves, which helps them develop their narrative writing skills. This level of (corroborated) student-generated information, further presents opportunities to leverage more individualised means of capturing data for better connected (to other HE record systems) for more sophisticated data analysis.

With the aid of social computing technologies, a gamified, online platform where students create their own portfolio of achievements (Hamari, Koivisto and Sarsa, 2014), learning gain (McGrath et al, 2015) could be tracked at personal as well as group levels. Chevalier et al , 2009) support that students' own self-awareness and perception of achievement in relation to employability and enterprise are key elements of HE learning gain, which could be facilitated by enabling students to competitively review each other's achievements, using “smart learning environments” (Pesare, Roselli, Corriero and Rossano, 2016).

"All of the studies in education/learning contexts considered the learning outcomes of gamification as mostly positive, for example, in terms of increased motivation and engagement in the learning tasks as well as enjoyment over them. 
However, at the same time, the studies pointed to negative outcomes which need to be paid attention to, such as the effects of increased competition, task evaluation difficulties, and design features” (Hamari et al, 2014, p3028).

Such a student self-populated system would generate potential sets of 'big-data', which could be used to evaluate "learner-analytics" similar to systems used in the corporate world by employers (Giacumo and Breman, 2016; Perryer, Celestine, Scott-Ladd and Leighton, 2016). Used effectively, such data could provide a basis upon which to stimulate more immediate one-to-one conversations between students and personal tutors, highlighting where patterns of behaviour might be contributing towards lower performance.

\section{Limitations and future research}

It is contended, to be equipped for lifelong learning, students and graduates must be prepared to capitalise on opportunities present in HE by developing an 'AGILE' mindset. Thus this paper provides an exploration of a range of literature and models and contributes a new mindset model for E\&E learning purposes, yet it did not include empirical data, nor has the model itself undergone rigorous objective testing.

Future research needs to encompass longitudinal views of alumni from various country, subject and demographic profile perspectives, in order to generate greater understanding of the perceived value of enterprise education as well as identifying enhanced ways of linking employability and entrepreneurial outcomes to encourage improved measurement methods. Finally, empirical testing of the 'AGILE' mindset model in various settings could offer a student-generated glossary of terms which could be used to help them develop a narrative of E\&E gains which could enhance how they portray themselves for employers or as self-employed professionals.

\section{Declaration of conflicting interests}

The author(s) declared no potential conflicts of interest with respect to the research, authorship, and/or publication of this article.

\section{Funding}

The author(s) received no financial support for the research, authorship, and/or publication of this article.

\section{References}

Amabile T and Kramer S (2011) The Power Of Small Wins. Harvard Business Review 89(5):70-80.

Baumeister RF (2013) Writing a literature review. In The Portable Mentor (pp. 119-132). Springer New York.

Blenker P, Frederiksen S, Korsgaard S, Muller S, Neergaard H and Thrane C (2012) Entrepreneurship as Everyday Practice: Towards a Personalized Pedagogy of Enterprise Education, Industry And Higher Education, 26(6):417-430. 
Boon J, Van der Klink M and Janssen J (2013) Fostering intrapreneurial competencies of employees in the education sector. International Journal of Training and Development, 17(3), pp.210-220.

Braun V and Clarke V (2006) Using thematic analysis in psychology. Qualitative research in psychology, 3(2), pp.77-101.

Bridgstock R (2009) The graduate attributes we've overlooked: Enhancing graduate employability through career management skills. Higher Education Research \& Development, 28(1), pp.31-44.

Brooks R and Everett G (2008) The impact of higher education on lifelong learning. International Journal of Lifelong Education, 27(3), pp.239-254.

Caza A, Brower HH and Wayne JH (2015) Effects of a holistic, experiential curriculum on business students' satisfaction and career confidence. The International Journal of Management Education, 13(1), pp.75-83.

Chevalier A, Gibbons S, Thorpe A, Snell M and Hoskins S (2009) Students' academic self-perception. Economics of Education Review, 28(6), pp.716-727.

Ciuhureanu AT, Gorski H and Balteş N (2011) Study on the needs of competencies and abilities for the graduates 'adaptation to the requirements of the labour market in the context of Europe 2020 strategy. Of the university of Petroşani $\sim$ Economics $\sim$, p.35. Clinton M, Totterdell P and Wood S (2006) A grounded theory of portfolio working Experiencing the smallest of small businesses. International Small Business Journal, 24(2), pp. 179-203.

Crossman JE and Clarke M (2010) International experience and graduate employability: stakeholder perceptions on the connection. Higher Education, 59(5), pp. 599-613. Cumming J (2010) Contextualised performance: Reframing the skills debate in research education. Studies in Higher Education, 35(4), pp.405-419.

Dacre Pool L and Sewell P (2007) The key to employability: developing a practical model of graduate employability. Education + Training, 49(4), pp.277-289.

Degn L (2015) Identity constructions and sensemaking in higher education-a case study of Danish higher education department heads. Studies in Higher Education, 40(7):11791193.

Dweck C (2017) Mindset: changing the way you think to fulfil your potential. Robinson, Hachette, London.

Dweck C (2016) What having a "growth mindset” actually means. Harvard Business. Retrieved from: https://hbr. org/2016/01/what-having-a-growth-mindset-actually-means. Faggio G and Silva O (2014) Self-employment and entrepreneurship in urban and rural labour markets. Journal of Urban Economics, 84, pp.67-85.

Falck O, Heblich S and Luedemann E (2012) Identity and entrepreneurship: do school peers shape entrepreneurial intentions? Small Business Economics 39(1):39-59.

Fletcher-Brown J, Knibbs K and Middleton K (2015) Developing “employagility”: the 3Es case for live-client learning. Higher Education, Skills and Work-Based Learning, 5(2), pp.181-195.

Geneva: International Labour Organization (ILO) (2017. World employment social outlook. Retrieved from:http://www.ilo.org/wcmsp5/groups/public/---dgreports/--dcomm/--publ/documents/publication/wcms_541211.pdf 
Giacumo LA and Bremen J (2016) Emerging evidence on the use of big data and analytics in workplace learning: A Systematic Literature Review. Quarterly Review of Distance Education, 17(4), p.21-38.

Gibb A, Hannon P, Price A and Robertson I (2014) A compendium of pedagogies for teaching entrepreneurship. International entrepreneurship educators program.

Guile D and Lahiff A (2013) Internship: Conventional Wisdom, Models \& Recommendations. London: Great Britain.

Hamari J, Koivisto J and Sarsa H (2014) January. Does gamification work?--a literature review of empirical studies on gamification. In: System Sciences (HICSS) 47th Hawaii International Conference, Hawaii, USA, 2014. (pp. 3025-3034) IEEE.

Harrison RT and Leitch CM (2005) Entrepreneurial learning: Researching the interface between learning and the entrepreneurial context. Entrepreneurship theory and practice, 29(4), pp.351-371.

Hart A, Davies C, Aumann K, Wenger E, Aranda K, Heaver B. and Wolff D (2013)

Mobilising knowledge in community- university partnerships: What does a community of practice approach contribute? Contemporary Social Science, 8(3):278-291.

Helyer R and Lee D (2014) The role of work experience in the future employability of higher education graduates. Higher Education Quarterly, 68(3), pp.348-372.

Hernández-López L, García-Almeida DJ, Ballesteros-Rodríguez JL and De Saá-Pérez P (2016) Students' perceptions of the lecturer's role in management education: Knowledge acquisition and competence development. The International Journal of Management Education, 14(3), pp.411-421.

Higher Education Achievement Report (HEAR), (2016). Retrieved from http://www.hear.ac.uk/about

Higher Education Statistics Agency (HESA), (2016) Destination of leavers from higher education report (DLHE) Students in Higher Education, London, UK.

Hinchliffe GW and Jolly A (2011) Graduate identity and employability. British Educational Research Journal, 37(4), pp.563-584.

Holmes L (2013a) Competing perspectives on graduate employability: possession, position or process?. Studies in Higher Education, 38(4), pp.538-554.

Holmes L (2013b) Realist and relational perspectives on graduate identity and employability: a response to Hinchliffe and Jolly. British Educational Research Journal, 39(6), pp.1044-1059.

Jackson D (2015) Employability skill development in work-integrated learning: Barriers and best practice. Studies in Higher Education, 40(2), pp.350-367.

Jensen DH and Jetten J (2015) Bridging and bonding interactions in higher education: social capital and students' academic and professional identity formation. Frontiers in psychology, 6(126), pp1-11.

Johnston B (2003) The shape of research in the field of higher education and graduate employment: Some issues. Studies in Higher Education, 28(4), pp.413-426.

Jones K (2004) Mission drift in qualitative research, or moving toward a systematic review of qualitative studies, moving back to a more systematic narrative review. Qualitative Report, 9(1), pp.95-112.

Jones P, Jones A, Skinner H and Packham G (2013). Embedding enterprise: a business school undergraduate course with an enterprise focus. Industry and Higher Education, 27(3), pp.205-215. 
Jones P, Pickernell D, Fisher R and Netana C (2017) A tale of two universities: graduates perceived value of entrepreneurship education. Education + Training, 59(7), pp.689-705.

Kakouris A (2015) Entrepreneurship pedagogies in lifelong learning: emergence of criticality?. Learning, Culture and Social Interaction, 6, pp.87-97.

Kalfa S and Taksa L (2015) Cultural capital in business higher education: reconsidering the graduate attributes movement and the focus on employability. Studies in Higher Education, 40(4), pp.580-595.

Knibbs K (2015) What is the role of university service providers in developing marketing student employability? Evidence from 'Enablers'. In: Proceedings of Academy of Marketing Conference, The Magic in Marketing, University of Limerick, Ireland, July 2015. ISBN:9781905952649. Available at:

https://www.academyofmarketing.org/conference/conference-history/conference-2015/ Knibbs K, Fletcher-Brown J and Middleton K (2015) Introducing EmployaGility sharing ideas for engaging multiple stakeholders in the teaching, learning, employment journey. In: British Academy of Management Conference, University of Portsmouth, UK, September 2015. Available at: https://www.bam.ac.uk/civicrm/event/info?id=2886 Knight PT and Yorke M (2003) Employability and good learning in higher education. Teaching in Higher education, 8(1), pp.3-16.

Kunert KJ, Okole B, Vorster BJ, Brewin NJ and Cullis CA (2012) A general model for training the next generation of Biotechnology entrepreneurs based on recent experience of USA-UK-South Africa collaborations. Journal of Commercial Biotechnology, 18,(3), pp.62-66.

Lahm Jr RJ and Heriot KC (2013) Creating an entrepreneurship internship program: A case study. Journal of Entrepreneurship Education, 16, p.73-98.

Leibowitz B, Ndebele C and Winberg C (2014) It's an amazing learning curve to be part of the project': exploring academic identity in collaborative research. Studies in Higher Education, 39(7), pp.1256-1269.

Marginson S (2014) Student self-formation in international education. Journal of Studies in International Education .18(1), pp.6-22.

McGrath CH, Guerin B, Harte E, Frearson M,. and Manville C (2015) Learning gain in higher education. Santa Monica, California, United States of America: RAND Corporation.

Minniti M and Bygrave W (2001) A dynamic model of entrepreneurial learning. Entrepreneurship: Theory and practice, 25(3), pp.5-5.

Moore T and Morton J (2017) The myth of job readiness? Written communication, employability, and the 'skills gap'in higher education. Studies in Higher

Education, 42(3), pp.591-609.

Nabi G, Liñán F, Fayolle A, Krueger N and Walmsley A (2017) The Impact of Entrepreneurship Education in Higher Education: A Systematic Review and Research Agenda. Academy Of Management Learning \& Education, 16(2), pp.277-299. O'Leary S (2012) Impact of entrepreneurship teaching in higher education on the employability of scientists and engineers. Industry and Higher Education, 26(6), pp.431442.

Poblete C (2018) Growth expectations through innovative entrepreneurship: The role of 
subjective values and duration of entrepreneurial experience. International Journal of Entrepreneurial Behavior \& Research, 24(1), pp.191-213.

Perryer C, Celestine NA, Scott-Ladd B and Leighton C (2016) Enhancing workplace motivation through gamification: Transferrable lessons from pedagogy. The International Journal of Management Education, 14(3), pp.327-335.

Pesare E, Roselli T, Corriero N and Rossano V (2016) Game-based learning and Gamification to promote engagement and motivation in medical learning contexts. Smart Learning Environments, 3(1), p.5.

Pickernell D, Packham G, Jones P, Miller C and Thomas B (2011) Graduate entrepreneurs are different: they access more resources?. International Journal of Entrepreneurial Behavior \& Research, 17(2), pp.183-202.

Pickernell, D Senyard J, Jones P, Packham G, and Ramsey E (2013) New and young firms: Entrepreneurship policy and the role of government-evidence from the Federation of Small Businesses survey. Journal of Small Business and Enterprise Development, 20(2), pp.358-382.

Pittaway L and Cope J (2007) Entrepreneurship education: a systematic review of the evidence. International Small Business Journal. 25(5), pp.479-510.

Plumb I and Zamfir A (2011) A Possible Model for Developing Students' Skills within the Knowledge-Based Economy. Amfiteatru Economic, 13(30), pp.482-496.

Porcheret M, Main C, Croft P, McKinley R, Hassell A and Dziedzic K (2014)

Development of a behaviour change intervention: a case study on the practical application of theory. Implementation Science, 9(42):1-11.

Procter C (2012) Peer mentoring to secure student placements. Higher Education, Skills And Work-Based Learning, 2(2): 121-131.

Quality Assurance Agency (QAA), (2012). Enterprise and Entrepreneurship Education. Guidance for UK Higher Education Providers. United Kingdom.

Quinitini G and Pouliakas K (2014) Matching skills and labour market needs. Building Social Partnerships for Better Skills and Better Jobs. CEDEFOP (European Centre for the Development of Vocational Training. analysis of PIAAC data. Global Agenda Council on Employment, January 22-25, at Davos-Klosters, Switzerland.

Rae D (2005) Entrepreneurial learning: a narrative-based conceptual model. Journal Of Small Business And Enterprise Development, 12(3), pp.323-335.

Rae D (2007) Connecting enterprise and graduate employability: challenges to the higher education culture and curriculum?. Education + Training, 49(8/9), pp.605-619.

Rae D, Martin L, Antcliff L and Hannon P (2012) Enterprise and entrepreneurship in English higher education: 2010 and beyond. Journal of Small Business and Enterprise Development 19(3): 380-401.

Rae D (2017) Entrepreneurial learning: peripherality and connectedness. International Journal of Entrepreneurial Behavior \& Research, 23(3), pp.486-503

Roulin N and Bangerter A (2013) Students' use of extra-curricular activities for positional advantage in competitive job markets. Journal of Education and Work, 26(1), pp.21-47.

Rowe F (2014) What literature review is not: diversity, boundaries and recommendations. European Journal of Information Systems, 23(3), pp.241-255. 
Sarasvathy S, Kumar K, York JG and Bhagavatula S (2014) An effectual approach to international entrepreneurship: Overlaps, challenges, and provocative possibilities. Entrepreneurship Theory and Practice, 38(1), pp.71-93.

Scott J, Penaluna A and Thompson J (2016) A critical perspective on learning outcomes and the effectiveness of experiential approaches in entrepreneurship education : Do we innovate or implement?. Education + Training, 58(1), pp.82-.93

Soetanto D (2017) Networks and entrepreneurial learning: coping with difficulties. International Journal of Entrepreneurial Behavior \& Research, 23(3), pp.547-565. Stein J and Irvine A (2015) Career Preparedness and Lifelong Learning: A Global Perspective. Available at: http://hdl.voced.edu.au/10707/384353 (accessed 20 October 2017)

Storey DJ (2011) Optimism and chance: The elephants in the entrepreneurship room. International Small Business Journal, 29(4), pp.303-321.

Thompson LJ, Clark G, Walker M and Whyatt JD (2013) 'It's just like an extra string to your bow': Exploring higher education students' perceptions and experiences of extracurricular activity and employability. Active Learning in Higher Education, 14(2), pp.135-147.

Tomlinson M (2012) Graduate employability: A review of conceptual and empirical themes. Higher Education Policy, 25(4), pp.407-431.

Trede F, Macklin R and Bridges D (2012) Professional identity development: a review of the higher education literature. Studies in Higher Education, 37(3), pp.365-384.

Tsai YS and Gasevic D (2017) March Learning analytics in higher education--challenges and policies: a review of eight learning analytics policies. In: Proceedings of the Seventh International Learning Analytics \& Knowledge Conference (pp. 233-242) ACM.

Tymon A (2013) The student perspective on employability. Studies in higher education, 38(6), pp.841-856.

Villar E and Albertin P (2010) 'It is who knows you'. The positions of university students regarding intentional investments in social capital. Studies in Higher Education, 35(2), pp. 137-54.

Wenger E (2010) Communities of practice and social learning systems: the career of a concept. Social learning systems and communities of practice, 3, pp.179-198.

Wilson N and Martin L (2015) Entrepreneurial opportunities for all? Entrepreneurial capability and the Capabilities Approach. The International Journal of Entrepreneurship and Innovation ,16(3), pp.159-169.

Woodall T, Hiller A and Resnick S (2014) Making sense of higher education: students as consumers and the value of the university experience. Studies in Higher Education, 39(1), pp.48-67.

Woollard D (2010) Towards a theory of university entrepreneurship: Developing a theoretical model. Industry and Higher Education, 24(6), pp.413-427.

Wright J, Brinkley I and Clayton N (2010) Employability and Skills in the UK: Redefining the Debate. London: The Work Foundation. Citation: Senior C, Reddy P and Senior $R$ (2014) The relationship between student employability and student engagement: working toward a more unified theory. Front. Psychol, 5, p.238. 
Yeager D and Dweck C (2012) Mindsets That Promote Resilience: When Students Believe That Personal Characteristics Can Be Developed. Educational Psychologist, 47(4), pp. 302-314.

Yorke M and Knight P (2004) Self-theories: some implications for teaching and learning in higher education. Studies in Higher Education, 29(1), pp.25-37.

Yorke M and Knight P (2006) Curricula for economic and social gain. Higher Education. 51(4), pp.565-588.

Young D (2014) Enterprise for all: the relevance of enterprise in education. Department for Business Innovation and Skills, United Kingdom. 